Article

\title{
Electrocatalytic activity of porous nanostructured Fe/Pt-Fe electrode for methanol electrooxidation in alkaline media
}

\author{
Javad Hosseini a, Mehdi Abdolmaleki ${ }^{b}$, Hamid Reza Pouretedal a,*, Mohammad Hossein Keshavarz ${ }^{a}$ \\ a Department of Chemistry, Malek-ashtar University of Technology, Shahin-shahr, Isfahan, Iran \\ b Faculty of Science, Department of Chemistry, Sayyed Jamaleddin Asadabadi University, Asadabad, Iran
}

A R T I C L E I N F O

Article history:

Received 23 December 2014

Accepted 17 March 2015

Published 20 July 2015

Keywords:

Methanol electro-oxidation

Nanostructured Fe/Pt-Fe

Electrocatalytic behavior

Galvanic replacement

Cyclic voltammetry

Direct methanol fuel cell

\begin{abstract}
A B S T R A C T
An electrochemical approach to fabricate a nanostructured Fe/Pt-Fe catalyst through electrodeposition followed by galvanic replacement is presented. An Fe/Pt-Fe nanostructured electrode was prepared by deposition of Fe-Zn onto a Fe electrode surface, followed by replacement of the Zn by $\mathrm{Pt}$ at open-circuit potential in a Pt-containing alkaline solution. Scanning electron microscopy and energy-dispersive $\mathrm{X}$-ray techniques reveal that the $\mathrm{Fe} / \mathrm{Pt}-\mathrm{Fe}$ electrode is porous and contains $\mathrm{Pt}$. The electrocatalytic activity of the Fe/Pt-Fe electrode for oxidation of methanol was examined by cyclic voltammetry and chronoamperometry. The electrooxidation current on the Fe/Pt-Fe catalyst is much higher than that on flat Pt and smooth Fe catalysts. The onset potential and peak potential on the Fe/Pt-Fe catalyst are more negative than those on flat Pt and smooth Fe electrodes for methanol electrooxidation. All results show that this nanostructured Fe/Pt-Fe electrode is very attractive for integrated fuel cell applications in alkaline media.
\end{abstract}

(C) 2015, Dalian Institute of Chemical Physics, Chinese Academy of Sciences. Published by Elsevier B.V. All rights reserved.

\section{Introduction}

Direct alcohol fuel cells (DAFCs) show great potential for use as clean, high-efficiency future power sources because of their easy storage, portability, and high specific energy [1,2]. Fuels based on the oxidation of small organic molecules require electrocatalysts to achieve the current density needed for commercial fuel cell applications. Among electrocatalysts, Pt has received considerable attention because of its excellent electrocatalytic characteristics. However, the low poisoning tolerance of $\mathrm{Pt}$ for the electrooxidation of CO-like intermediates and high price prevent its commercialization in DAFCs. To date, a widely adopted solution to these problems is to use Pt-based alloys or nanocomposites, which can decrease the content of $\mathrm{Pt}$ and substantially enhance the performance of the catalysts through a bifunctional mechanism [3-7].

$\mathrm{Ni}$ is suitable to alloy with noble metals because it can en- hance the activity of catalysts for alcohol oxidation by lowering the electronic binding energy of the noble metal [8-14]. An alternative to $\mathrm{Ni}$ is $\mathrm{Fe}$, which is a cheap and environmentally benign alloy metal that has also been reported to improve the electrocatalytic activity and stability of Pt electrodes [15]. It has been found that $\mathrm{Fe}^{3+}$-containing compounds in alkaline solution can improve the electrocatalytic activity of Pt for methanol oxidation because they can alter the surface state of $\mathrm{Pt}$ and promote the adsorption of $\mathrm{OH}$ species, which are necessary to enhance the oxidation of CO-like intermediates on the Pt catalyst [16].

Recently, porous bimetallic nanostructures have received considerable interest because of their high specific surface, low density, and low cost [17-20]. Bimetallic catalysts can exhibit higher activity and stability than monometallic ones. The galvanic replacement reaction provides a very simple and effective method to prepare porous bimetallic nanostructures with a

* Corresponding author. Tel: +98-314-5912253; Fax: +98-314-5220420; E-mail: HR_POURETEDAL@mut-es.ac.ir 
lower standard electrode potential than that of the target material.

In this paper, we fabricate porous $\mathrm{Fe} / \mathrm{Pt}-\mathrm{Fe}$ nanostructures via a facile galvanic replacement reaction using $\mathrm{Zn}$ from an Fe/Zn-Fe electrode. First, Fe-Zn coating is formed on Fe by electrodeposition to obtain the Fe/Zn-Fe electrode. Porous $\mathrm{Fe} / \mathrm{Pt}-\mathrm{Fe}$ nanostructures are then produced by exposing the Fe/Zn-Fe electrode to an alkaline aqueous solution of Pt salt. We investigate the catalytic activity of the porous Fe/Pt-Fe nanostructures for electrooxidation of methanol in alkaline solution.

\section{Experimental}

\subsection{Catalyst preparation}

All reagents used were of analytical grade provided by Merck and used without further purification. For each experiment, a freshly prepared electrode and solution was used. The $\mathrm{Fe} / \mathrm{Pt}-\mathrm{Fe}$ catalysts were prepared through electrodeposition and galvanic replacement processes. $\mathrm{Cu}$ electrodes were cut and mounted in polyester resin except for a surface area of 1 $\mathrm{cm}^{2}$ that was exposed for measurements. Electrical connection was provided by $\mathrm{Cu}$ wire. Before electrodeposition, the electrode surfaces were polished with emery paper (2500 grit size), washed with distilled water, thoroughly degreased in a $30 \mathrm{wt} \% \mathrm{NaOH}$ solution for $5 \mathrm{~min}$, washed with distilled water, dipped in $10 \mathrm{wt} \% \mathrm{H}_{2} \mathrm{SO}_{4}$ solution for $1 \mathrm{~min}$, washed with distilled water, and finally immersed in the bath solution. The plating baths and conditions used to prepare the smooth $\mathrm{Fe}$ and $\mathrm{Fe} / \mathrm{Fe}-\mathrm{Zn}$ coatings are described in Table 1.

After deposition, the electrodes were rinsed with distilled water to remove residual bath chemicals and unattached particles. Pt deposition was performed simply by immersing the $\mathrm{Fe} / \mathrm{Zn}-\mathrm{Fe}$ electrode in a $30 \mathrm{wt} \% \mathrm{NaOH}$ solution of $\mathrm{H}_{2} \mathrm{PtCl}_{6}$ salt with a concentration of $1 \mathrm{mmol} / \mathrm{L}$ for $48 \mathrm{~h}$ at room temperature.

The standard reduction potential of the $\mathrm{PtCl}_{6}{ }^{2-} / \mathrm{Pt}$ pair $(0.735 \mathrm{~V}$ vs SHE) is higher than the reduction potential of the $\mathrm{Zn}^{2+} / \mathrm{Zn}$ pair ( $-0.762 \mathrm{~V}$ vs SHE), so it can be reduced by $\mathrm{Zn}$ as shown in the following equation:

$$
2 \mathrm{Zn}+\mathrm{PtCl}_{6}{ }^{2-} \rightarrow \mathrm{Pt}+2 \mathrm{Zn}^{2+}+6 \mathrm{Cl}^{-}
$$

Finally, the electrode was removed from the solution and washed thoroughly with doubly distilled water.

Table 1

Experimental conditions used in the electrodeposition of smooth $\mathrm{Fe}$ and $\mathrm{Fe} / \mathrm{Fe}-\mathrm{Zn}$ coatings.

\begin{tabular}{lcc}
\hline \multirow{2}{*}{$\begin{array}{l}\text { Composition and operating } \\
\text { conditions }\end{array}$} & \multicolumn{2}{c}{ Type of coating } \\
\cline { 2 - 3 } $\mathrm{FeSO}_{4} \cdot 7 \mathrm{H}_{2} \mathrm{O}(\mathrm{g} / \mathrm{L})$ & 250 & $\mathrm{Fe} / \mathrm{Fe}-\mathrm{Zn}$ \\
$\left(\mathrm{NH}_{4}\right)_{2} \mathrm{Fe}\left(\mathrm{SO}_{4}\right)_{2} \cdot 6 \mathrm{H}_{2} \mathrm{O}(\mathrm{g} / \mathrm{L})$ & 280 & 250 \\
$\mathrm{ZnSO}_{4} \cdot 7 \mathrm{H}_{2} \mathrm{O}(\mathrm{g} / \mathrm{L})$ & - & 250 \\
Current density $\left(\mathrm{mA} / \mathrm{cm}^{2}\right)$ & 70 & 30 \\
Temperature $\left({ }^{\circ} \mathrm{C}\right)$ & 70 & 30 \\
pH & $2-3$ & $2-3$ \\
Time (min) & 30 & 30 \\
\hline
\end{tabular}

\subsection{Catalyst characterization}

Scanning electron microscope (SEM) images of samples were obtained at different magnifications by an SEM (Tescan Mira3). The composition of samples was determined by energy-dispersive X-ray (EDX) spectroscopy, which was carried out on the same SEM.

\subsection{Electrochemical studies}

Electrochemical studies were performed using a conventional electrochemical cell with a standard three-electrode arrangement. A Pt sheet with a geometric area of about $20 \mathrm{~cm}^{2}$ was used as the counter electrode. All potentials were measured against an $\mathrm{Ag} / \mathrm{AgCl} / \mathrm{KCl}$ (saturated) electrode. Cyclic voltammetry (CV) and chronoamperometry (CA) measurements were performed using a potentiostat/galvanostat (SAMA 500-C Electrochemical Analysis System, Sama, Iran) coupled with a Pentium IV personal computer to acquire the data. CV experiments were performed in the potential region from -0.8 to $0.6 \mathrm{~V}$ in $1 \mathrm{~mol} / \mathrm{L} \mathrm{NaOH}+x \mathrm{~mol} / \mathrm{L}$ methanol $(0.1 \leq x \leq 1)$ at 20-60 ${ }^{\circ} \mathrm{C}$. Before electrochemical measurement, solutions were degassed by purging with $\mathrm{N}_{2}$ for at least $10 \mathrm{~min}$.

\section{Results and discussion}

\subsection{Characterization of coatings}

SEM images of smooth $\mathrm{Fe}, \mathrm{Fe} / \mathrm{Zn}-\mathrm{Fe}$, and $\mathrm{Fe} / \mathrm{Pt}-\mathrm{Fe}$ electrodes are shown in Fig. 1. The smooth Fe electrode has a relatively homogeneous surface with low roughness and can be considered as a quasi-two-dimensional surface. Fig. 1(b) reveals that the surface of Fe is fully covered by a $\mathrm{Zn}$-Fe layer in the Fe/Zn-Fe electrode. The Fe/Zn-Fe coating is compact and has a porous structure. The morphology of the electrode surface changed considerably after the leaching-galvanic replacement process of $\mathrm{Zn}$ from the Fe/Zn-Fe electrode. Numerous cracks and pores appeared, which led to a high active surface area for methanol oxidation.

The surface EDX spectra of the electrodes are presented in Fig. 2. EDX analysis showed that the atomic composition of the coating before leaching and replacement was 13.51 at\% Fe and 86.49 at $\% \mathrm{Zn}$. After alkaline leaching-galvanic replacement, the atomic composition of the coating changed to 58.57 at $\% \mathrm{Fe}$, 12.31 at $\% \mathrm{Zn}$, and 29.12 at\% Pt. These results reveal that the Zn content decreased considerably after selective dissolution, which led to pore and crack formation, producing a highly porous surface suitable for methanol electrooxidation. The EDX results also confirm the presence of Pt particles on the surface of the film.

\subsection{Cyclic voltammetry}

The electrocatalytic activity of the nanostructured Fe/Pt-Fe, smooth $\mathrm{Fe}$, and flat Pt electrodes for methanol oxidation was evaluated by CV. Fig. 3 shows typical CVs obtained during methanol electrooxidation on the smooth $\mathrm{Fe}$, flat $\mathrm{Pt}$, and 


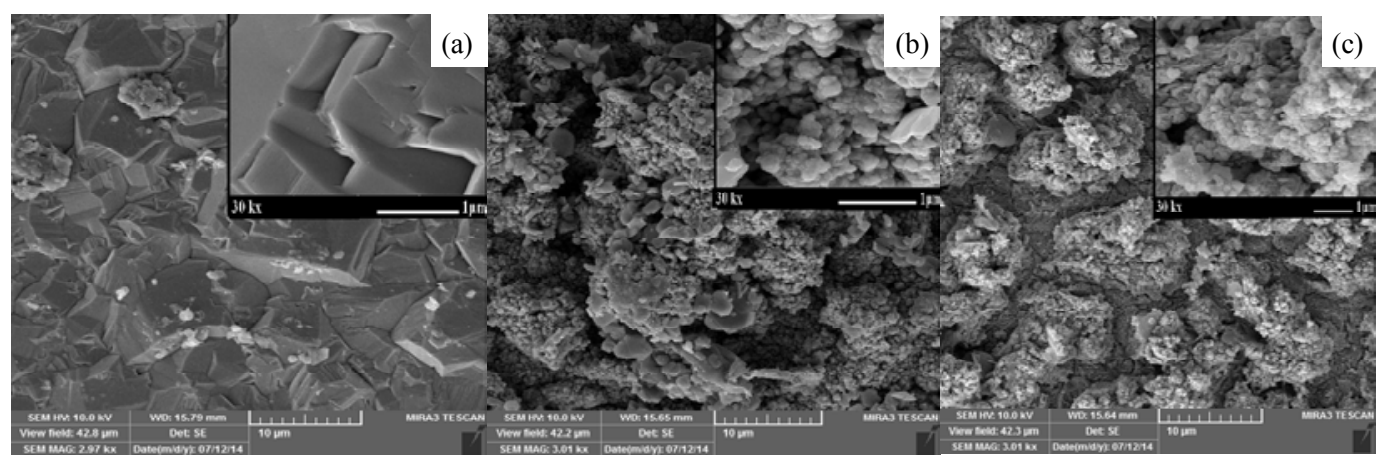

Fig. 1. SEM images of the surfaces of smooth Fe (a), Fe/Zn-Fe coating (b), and Fe/Pt-Fe coating (c) after the leaching-galvanic replacement process.
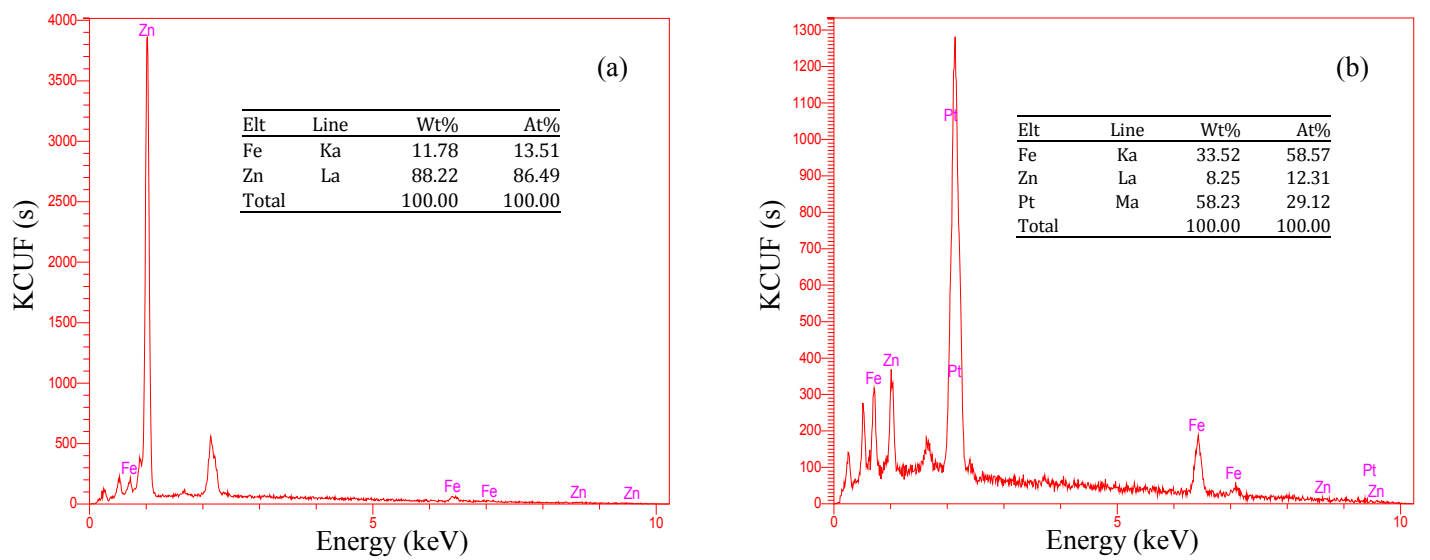

Fig. 2. EDX spectra obtained from the surfaces of $\mathrm{Fe} / \mathrm{Zn}-\mathrm{Fe}(\mathrm{a})$ and $\mathrm{Fe} / \mathrm{Pt}-\mathrm{Fe}$ electrodes (b) after the leaching-galvanic replacement process.

nanostructured $\mathrm{Fe} / \mathrm{Pt}-\mathrm{Fe}$ electrodes in $1 \mathrm{~mol} / \mathrm{L} \mathrm{NaOH}$ solution containing $0.1 \mathrm{~mol} / \mathrm{L}$ methanol at room temperature. CVs for the same electrodes in $1 \mathrm{~mol} / \mathrm{L} \mathrm{NaOH}$ without methanol under the same conditions are provided in the corresponding insets. The potential was swept between -0.8 and $0.5 \mathrm{~V}$ vs $\mathrm{Ag} / \mathrm{AgCl}$ at a scan rate of $50 \mathrm{mV} / \mathrm{s}$ during the experiments.

The inset in Fig. 3(a) shows that in the potential range from -0.8 to $0.5 \mathrm{~V}$, anodic and reduction peaks appear at -0.146 and
$-0.605 \mathrm{~V}$, respectively, in $1 \mathrm{~mol} / \mathrm{L} \mathrm{NaOH}$ solution without any methanol for the smooth Fe electrode. The appearance of an anodic peak with a broad shoulder in the potential region from 0.045 to $0.245 \mathrm{~V}$ is the main effect observed upon the addition $0.1 \mathrm{~mol} / \mathrm{L}$ methanol to the electrolyte. The anodic peak at $-0.146 \mathrm{~V}$ is attributed to hydrogen desorption, the cathodic peak at $-0.605 \mathrm{~V}$ is attributed to hydrogen evolution and the other peak with a broad shoulder is related to methanol elec-
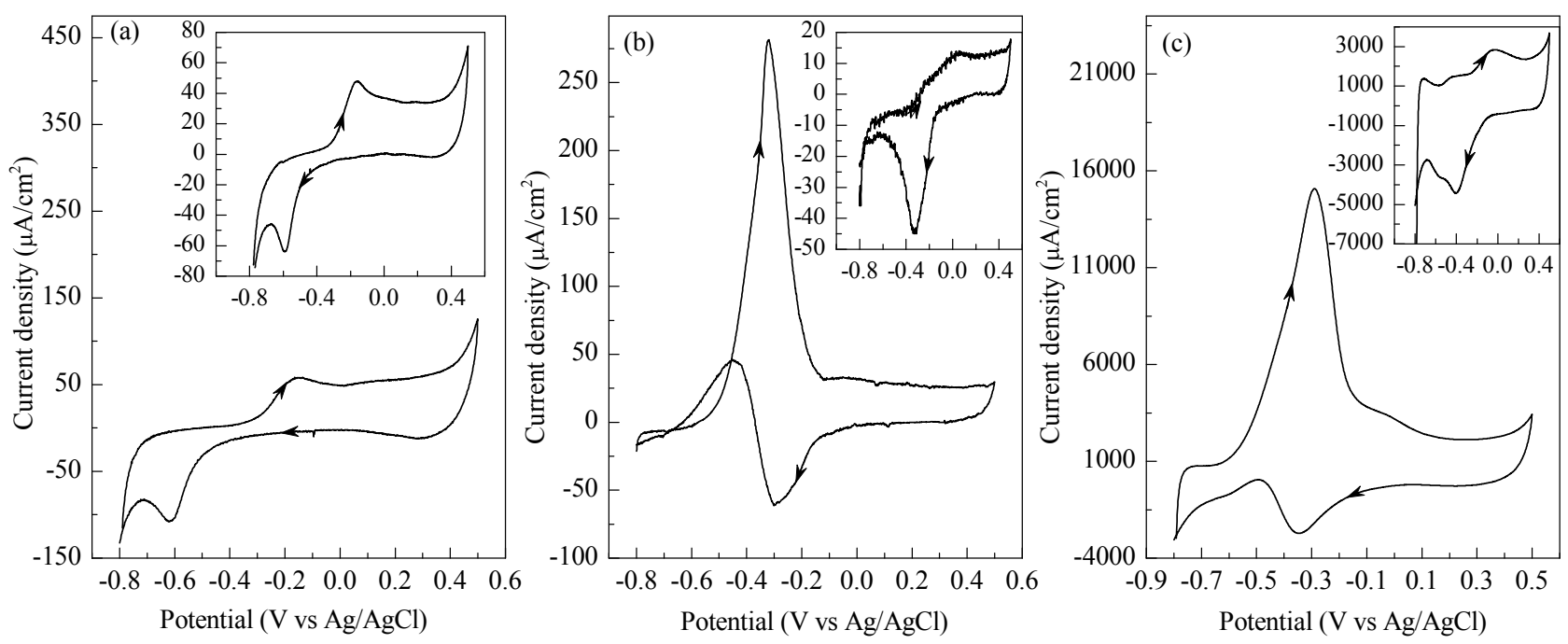

Fig. 3. CVs of smooth Fe (a), flat Pt (b), and nanostructured Fe/Pt-Fe electrodes (c) in an aqueous solution containing $1 \mathrm{~mol} / \mathrm{L} \mathrm{NaOH}$ and $0.1 \mathrm{~mol} / \mathrm{L}$ methanol at a potential scan rate of $50 \mathrm{mV} / \mathrm{s}$. CVs for the same electrodes without methanol in $1 \mathrm{~mol} / \mathrm{L} \mathrm{NaOH}$ at a scan rate of $50 \mathrm{mV} / \mathrm{s}$ are presented in the corresponding insets. 

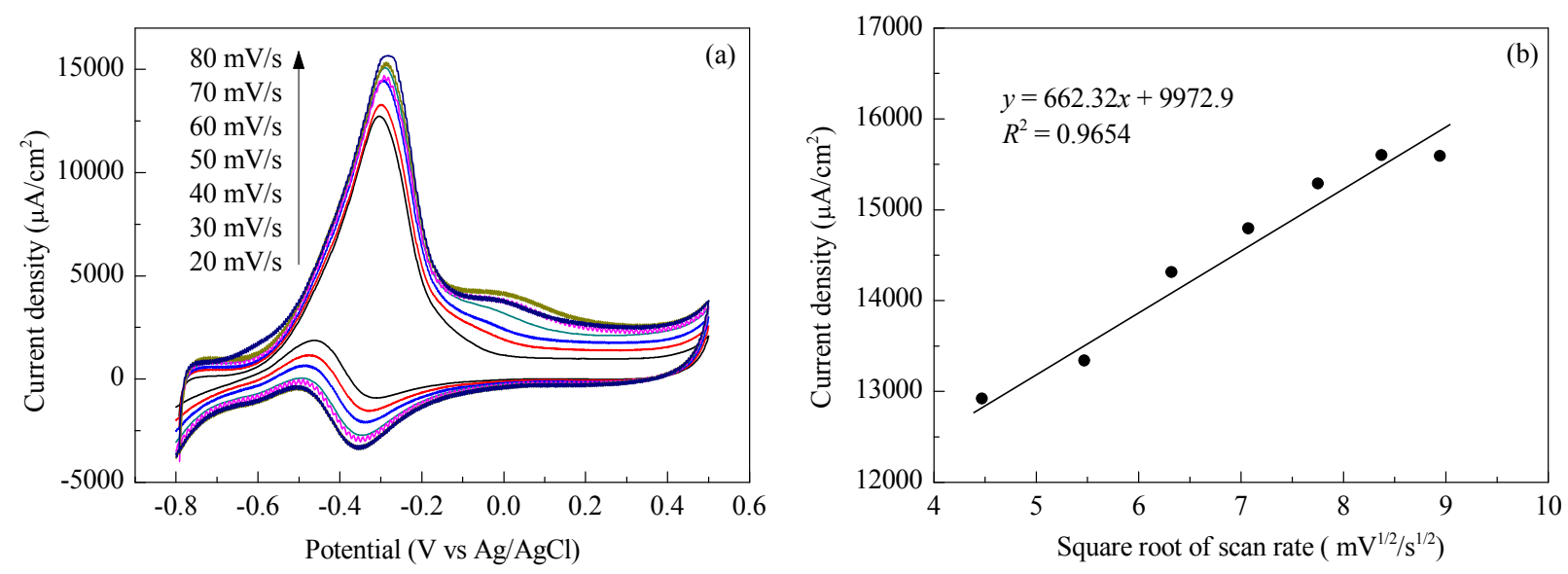

Fig. 4. (a) CVs obtained for the nanostructured Fe/Pt-Fe electrode in $1 \mathrm{~mol} / \mathrm{L} \mathrm{NaOH} / 0.1 \mathrm{~mol} / \mathrm{L}$ methanol at different scan rates. (b) Plot of methanol oxidation peak current on the porous Fe/Pt-Fe electrode against the square root of the scan rate.

trooxidation [21]. The peak current density is $0.055 \mathrm{~mA} / \mathrm{cm}^{2}$.

By comparison with the $\mathrm{CV}$ for the smooth Fe electrode in 1 $\mathrm{mol} / \mathrm{L} \mathrm{NaOH}$, the reduction current peaks of platinum oxide can be clearly observed for the flat Pt and Fe/Pt-Fe electrodes in Figs. 3(b) and (c), respectively. Meanwhile, methanol electrooxidation on the flat $\mathrm{Pt}$ and $\mathrm{Fe} / \mathrm{Pt}-\mathrm{Fe}$ electrodes can be characterized by two well-defined current peaks in the forward and reverse scans. In the forward scan, the oxidation peak corresponds to the oxidation of freshly chemisorbed species originating from methanol adsorption [22,23]. The reverse scan peak is primarily associated with the removal of carbonaceous species not completely oxidized in the forward scan rather than the oxidation of freshly chemisorbed species [24-27], although the origin of the reverse scan peak is still under debate.

The potential of the forward peak for the electrooxidation of methanol on the nanostructured Fe/Pt-Fe electrode was -0.305 $\mathrm{V}$ (vs $\mathrm{Ag} / \mathrm{AgCl}$ ), which is at more negative potential than -0.292 $\mathrm{V}$ (vs $\mathrm{Ag} / \mathrm{AgCl}$ ) for flat $\mathrm{Pt}$ and $0.085 \mathrm{~V}$ (vs $\mathrm{Ag} / \mathrm{AgCl}$ ) for the smooth Fe electrode. The peak current densities associated with methanol oxidation in the forward scan for Fe/Pt-Fe, flat $\mathrm{Pt}$, and smooth Fe were 14.97, 0.28, and $0.055 \mathrm{~mA} / \mathrm{cm}^{2}$, respectively. The electrocatalytic activities of the electrodes could therefore be ranked in the following order: smooth $\mathrm{Fe}<$ flat $\mathrm{Pt}$ $<$ Fe/Pt-Fe. The high peak oxidation current and low anodic peak potential for the Fe/Pt-Fe electrode reveal that this electrocatalyst is more active than the flat Pt and smooth Fe electrodes. This finding confirms that the leaching-galvanic replacement method can provide electrodes with a large electrochemically active area for methanol electrooxidation. Moreover, the higher catalytic currents obtained at more negative potentials on the Fe/Pt-Fe electrocatalyst than the other materials could potentially improve the efficiency of DAFCs.

The effect of scan rate on the CV behavior of the porous $\mathrm{Fe} / \mathrm{Pt}-\mathrm{Fe}$ nanostructured electrode in $1 \mathrm{~mol} / \mathrm{L} \mathrm{NaOH} / 0.1 \mathrm{~mol} / \mathrm{L}$ methanol solution is depicted in Fig. 4(a). Plots of forward peak current density against the square root of the scan rate for the Fe/Pt-Fe electrode are given in Fig. 4(b). The forward peak current density increases linearly with the square root of the scan rate, indicating a diffusion-controlled electrocatalytic oxidation process (Fig. 4(b)). The forward peak potential also shifted to more positive value with the square root of the scan rate, showing that an irreversible electrode reaction takes place on the Fe/Pt-Fe electrode surface.

Fig. 5(a) shows typical CVs for the Fe/Pt-Fe electrode as a
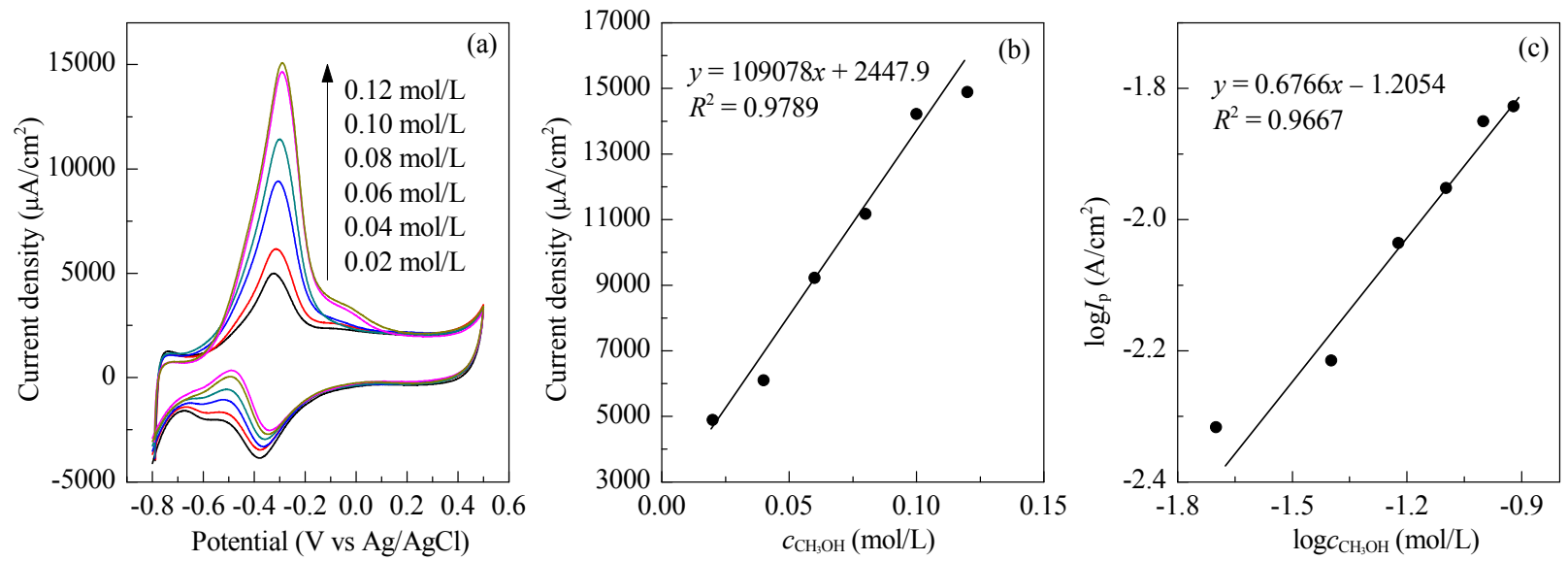

Fig. 5. (a) CVs of the porous $\mathrm{Fe} / \mathrm{Pt}$-Fe electrode from -0.8 to $0.5 \mathrm{~V} \mathrm{vs} \mathrm{Ag} / \mathrm{AgCl}$ at a scan rate of $50 \mathrm{mV} / \mathrm{s}$ for various concentrations of methanol. (b) Plot of methanol oxidation peak current on the porous Fe/Pt-Fe electrode against concentration of methanol. (c) Plot of $\log I_{\mathrm{p}}$ vs $\log \mathrm{CCH}_{\mathrm{C}} \mathrm{OH}$ obtained for the Fe/Pt-Fe electrode at a scan rate of $50 \mathrm{mV} / \mathrm{s}$. 
function of methanol concentration between 0.02 and 0.12 mol/L. The forward peak potential shifted slightly toward more positive values with increasing methanol concentration. The peak current density increased linearly with concentration, as illustrated in Fig. 5(b). The slope of this straight line is equal to the order of the reaction with respect to methanol according to the relationship [28]:

$$
\begin{gathered}
\text { Rate } \equiv I_{\mathrm{p}}=k c^{n} \\
\log I_{\mathrm{p}}=\log k+n \log c
\end{gathered}
$$

where $I_{\mathrm{p}}$ is the peak current density, $k$ is the reaction rate constant, $c$ is the bulk concentration of methanol, and $n$ is the reaction order. The reaction rate constant and reaction order of the nanostructured Fe/Pt-Fe electrode were 0.062 and 0.6766 , respectively (Fig. 5(c)).

The dependence of the electrocatalytic performance of the Fe/Pt-Fe electrode on electrolyte temperature was investigated in the temperature range of $20-60{ }^{\circ} \mathrm{C}$ by CV. Fig. 6 reveals that anodic current increased with temperature. Furthermore, some other specific behavior was also observed during methanol oxidation, such as negative shifts of the forward anodic oxidation and onset potential. The difference between onset potentials became smaller as the temperature increased. Fig. 6(b) shows an Arrhenius plot of $\ln i$ vs $T^{-1}$ for the Fe/Pt-Fe electrode. The apparent activation energy calculated from the slope of this plot was $12.58 \mathrm{~J} / \mathrm{mol}$. As the temperature increased, the electrooxidation current density increased [19,20,29,30]. This is attributed to an increase in the rate of charge transfer at the electrode/electrolyte interface as the temperature is raised.

\subsection{Chronoamperometry}

CA tests were conducted to compare the long-term performance of the catalysts towards methanol oxidation in 0.1 $\mathrm{mol} / \mathrm{L} \mathrm{NaOH}$ solution containing $0.1 \mathrm{~mol} / \mathrm{L}$ methanol for $200 \mathrm{~s}$. Fig. 7 shows the CA curves measured for the smooth Fe, flat Pt, and $\mathrm{Fe} / \mathrm{Pt}-\mathrm{Fe}$ catalysts at a constant potential of $-0.2 \mathrm{~V}$. During the initial stage, the potentiostatic current decreased rapidly for all catalysts, perhaps because of the formation of intermediate species such as $\mathrm{CO}_{a d s}, \mathrm{CH}_{3} \mathrm{OH}_{a d s}$, and $\mathrm{CHO}_{\text {ads }}$ during methanol oxidation. After a long period of operation, although the

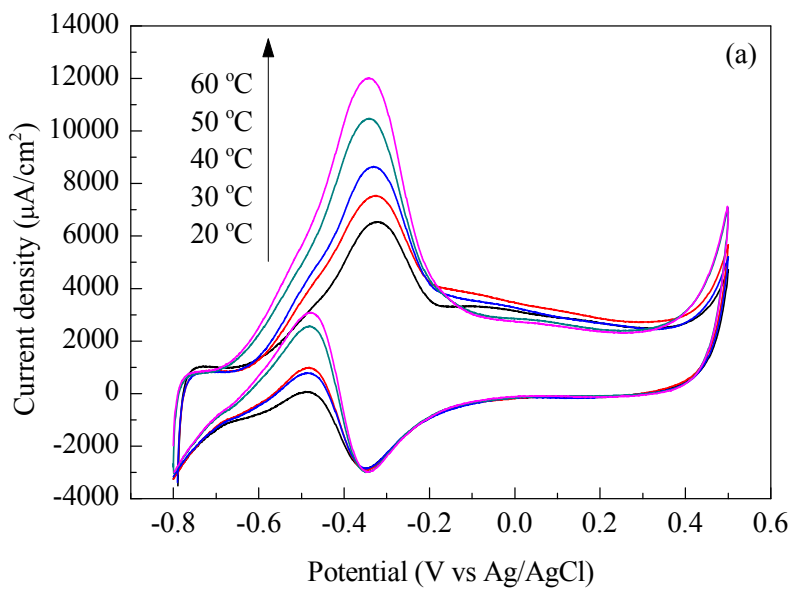

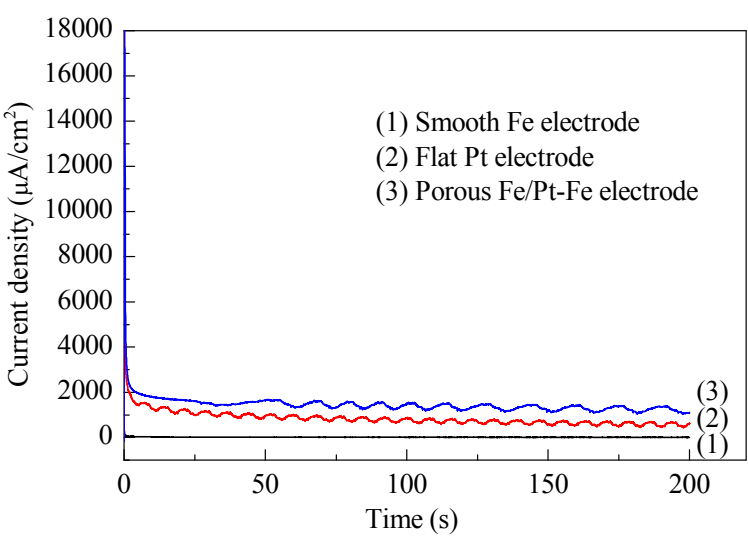

Fig. 7. CA curves for smooth Fe, flat Pt, and nanoporous Fe/Pt-Fe electrodes in $1 \mathrm{~mol} / \mathrm{L} \mathrm{NaOH} / 0.1 \mathrm{~mol} / \mathrm{L}$ methanol aqueous solutions.

current gradually decayed for all catalysts, Fe/Pt-Fe maintained a slightly higher current than the other catalysts. This indicates that the Fe/Pt-Fe catalyst has a higher catalytic activity and better antipoisoning ability than the other catalysts. The CA results show that the porous nanocrystalline Fe/Pt-Fe electrode exhibits more stable electrocatalytic activity towards methanol oxidation in alkaline media than smooth $\mathrm{Fe}$ and flat Pt electrodes.

\section{Conclusions}

A new porous Fe/Pt-Fe nanocatalyst was prepared by a simple galvanic replacement reaction of $\mathrm{Fe} / \mathrm{Zn}-\mathrm{Fe}$ in an alkaline Pt precursor solution. SEM showed that the alkaline leaching-galvanic replacement process produces a highly porous surface that was suitable for electrooxidation. The electrooxidation of methanol on the Fe/Pt-Fe electrode was systematically studied by CV and CA, and the results compared with those for flat Pt and smooth Fe electrodes. The onset potential for methanol oxidation on $\mathrm{Fe} / \mathrm{Pt}-\mathrm{Fe}(-0.635 \mathrm{~V}$ vs $\mathrm{Ag} / \mathrm{AgCl})$ was shifted to more negative values by 0.015 and $-0.605 \mathrm{~V}$ than those for smooth Fe and flat Pt electrodes, respectively. The current density for methanol oxidation on the Fe/Pt-Fe electrode $\left(14.97 \mathrm{~mA} / \mathrm{cm}^{2}\right)$ was greater than those observed for the

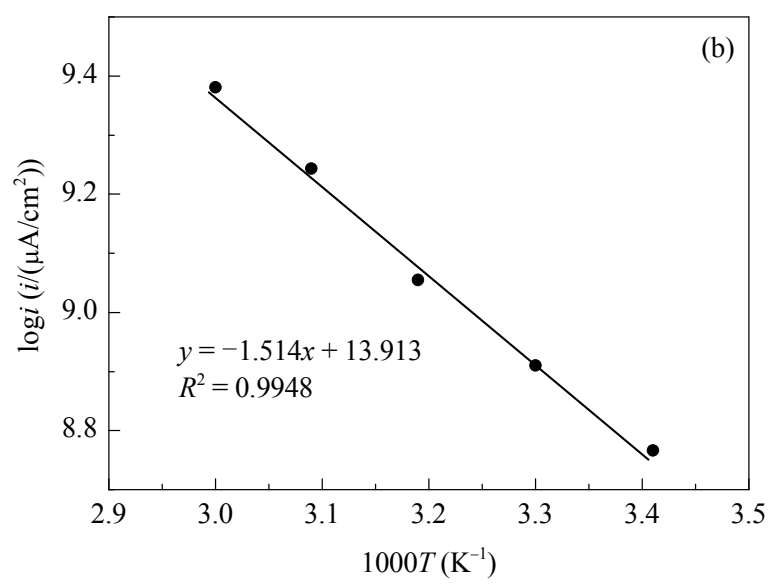

Fig. 6. (a) Effect of temperature on methanol oxidation by the $\mathrm{Fe} / \mathrm{Pt}-\mathrm{Fe}$ electrode in the range of $20-60{ }^{\circ} \mathrm{C}$ in $1 \mathrm{~mol} / \mathrm{L} \mathrm{NaOH} / 0.1 \mathrm{~mol} / \mathrm{L}$ methanol solution. (b) Arrhenius plot for methanol oxidation on the Fe/Pt-Fe electrode. 


\section{Graphical Abstract}

Chin. J. Catal., 2015, 36: 1029-1034 doi: 10.1016/S1872-2067(15)60841-5

Electrocatalytic activity of porous nanostructured Fe/Pt-Fe electrode for methanol electrooxidation in alkaline media

Javad Hosseini, Mehdi Abdolmaleki, Hamid Reza Pouretedal *,

Mohammad Hossein Keshavarz

Malek-ashtar University of Technology, Iran;

Sayyed Jamaleddin Asadabadi University, Iran

A porous Fe/Pt-Fe nanostructured electrode prepared by galvanic replacement exhibits higher electrocatalytic activity towards methanol oxidation than flat $\mathrm{Pt}$ and smooth Fe electrodes, which can be attributed to its high surface area.

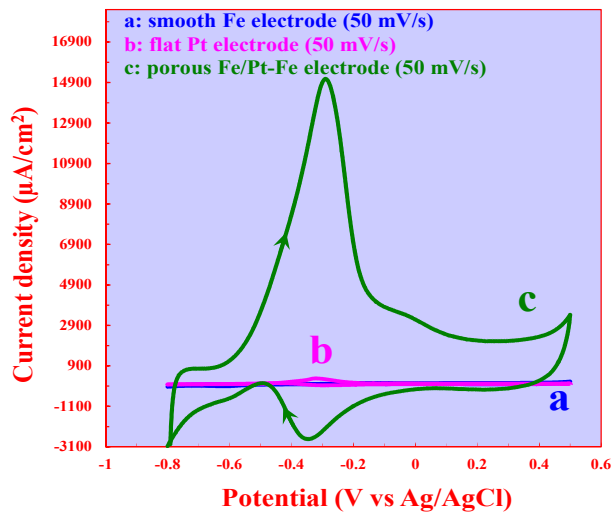

flat Pt $\left(0.28 \mathrm{~mA} / \mathrm{cm}^{2}\right)$ and smooth Fe $\left(0.055 \mathrm{~mA} / \mathrm{cm}^{2}\right)$ electrode because $\mathrm{Fe} / \mathrm{Pt}-\mathrm{Fe}$ possesses metal particles with a smaller average size, leading to larger surface area. CA demonstrated that although the current gradually decayed for all of the catalysts, Fe/Pt-Fe maintained a higher current and was more stable than flat Pt and smooth Fe. CA measurement results were consistent with those of $\mathrm{CV}$ and confirmed the porosity of the Fe/Pt-Fe electrode. This Fe/Pt-Fe catalyst can potentially be used as an anodic catalyst in DAFCs.

\section{Acknowledgments}

This work was supported by the Iranian Nanotechnology Society and the Office of the Vice-chancellor in Charge of Research at Malek-Ashtar University of Technology.

\section{References}

[1] Giz M J, Camara G A.J Electroanal Chem, 2009, 625: 117

[2] Kowal A, Gojkovic S L, Lee K S, Olszewski P, Sung Y E. Electrochem Commun, 2009, 11: 724

[3] Guo D J, Qiu X P, Chen L Q Zhu W T. Carbon, 2009, 47: 1680

[4] Lobato J, Canizares P, Rodrigo M A, Linares J J. Appl Catal B, 2009, 91: 269

[5] Bergamaski K, Gonzalez E R, Nart F C. Electrochim Acta, 2008, 53: 4396

[6] Jiang L, Hsu A, Chu D, Chen R. Int J Hydrogen Energy, 2010, 35: 365

[7] Kadirgan F, Beyhan S, Atilan T. Int J Hydrogen Energy, 2009, 34: 4312

[8] Li J, Tian W P, Shi L. Catal Lett, 2011, 141: 565

[9] Du C Y, Chen M, Wang W G, Yin G P, Shi P F. Electrochem Commun, 2010, 12: 843

[10] Lv X Y, Xu Z H, Yan Z X, Li X H. Electrocatalysis, 2011, 2(2): 82

[11] Qi Z, Geng H R, Wang X G, Zhao C C, Ji H, Zhang C, Xu J L, Zhang Z H.
J Power Sources, 2011, 196: 5823

[12] Antolini E, Salgado J R C, Gonzalez E R. J Power Sources, 2006, 155: 161

[13] Du Y S, Su J, Luo W, Cheng G Z. ACS Appl Mater Interfaces, 2015, 7: 1031

[14] Zhao Y C, Yang X L, Tian J N, Wang F Y, Zhan L. Int J Hydrogen Energy, 2010, 35: 3249

[15] Huang T, Liu J L, Li R S, Cai W B, Yu A S. Electrochem Commun, 2009, 11: 643

[16] Xu Z H, Hu J C, Yan Z X, Yang S B, Zhou J, Lu W. Electrochim Acta, 2009, 54: 3548

[17] Hosseini M G, Abdolmaleki M, Ashrafpoor S. Chin J Catal (催化学 报), 2012, 33: 1817

[18] Solmaz R, Döner A, Şahin İ, Yüce A O, Kardaş G, Yazıcı B, Erbil M. Int J Hydrogen Energy, 2009, 34: 7910

[19] Hosseini M G, Abdolmaleki M. Int J Hydrogen Energy, 2013, 38: 5449

[20] Hosseini M G, Abdolmaleki M, Ashrafpoor S. J Appl Electrochem, 2012, 42: 153

[21] Qiu C C, Shang R, Xie Y F, Bu Y R, Li C Y, Ma H Y. Mater Chem Phys, 2010, 120: 323

[22] Xu C W, Liu Y L, Yuan D S. Int J Electrochem Sci, 2007, 2: 674

[23] Lee Y W, Han S B, Park K W. Electrochem Commun, 2009, 11: 1968

[24] Singh R N, Singh A, Anindita. Int J Hydrogen Energy, 2009, 34: 2052

[25] Liu J P, Ye J Q, Xu C W, Jiang S P, Tong Y X. Electrochem Commun, 2007, 9: 2334

[26] Xu M W, Gao G Y, Zhou W J, Zhang K F, Li H L. J Power Sources, 2008, 175: 217

[27] Liang Z X, Zhao T S, Xu J B, Zhu L D. Electrochim Acta, 2009, 54: 2203

[28] Beden B, Kadirgan F, Lamy C, Leger J M. J Electroanal Chem Interf Electrochem, 1982, 142: 171

[29] Hosseini M G, Abdolmaleki M, Ashrafpoor S. Chin J Catal (催化学 报), 2013, 34: 1712

[30] Telli E, Solmaz R, Kardaş G. Russ J Electrochem, 2011, 47: 811 